\title{
1 Anodic oxidation for the remediation of soils polluted with 2 perchloroethylene
}

\section{Abstract} electrolysis.

\author{
M. Muñoz-Morales, C. Sáez, P. Cañizares, M.A. Rodrigo*
}

Department of Chemical Engineering. Faculty of Chemical Sciences and Technologies. University of Castilla-La Mancha. Campus Universitario s/n. 13071 Ciudad Real. SPAIN

BACKGROUND: This work focuses on the removal of perchloroethylene from soils spiked with this hazardous chlorinated hydrocarbon and oil by a combination of two technologies: soil washing and anodic oxidation with diamond electrodes. The first attains the transfer of the pollutant from the soil to a soil washing fluid, from which the organics are then efficiently removed.

RESULTS: Results show that high concentrations of Sodium Dodecyl Sulphate (SDS) are required in the soil washing fluid for an efficient extraction of the chlorinated hydrocarbon and this forces to apply electrolysis not only to the clarified liquid but to also to the interphase. Surfactant used interacts strongly with soil not only during the washing step but also during the electrolysis. This interaction seems to play a protective role against the oxidation of SDS. First moments of the electrolysis are rather complex and there are several processes which modifies importantly the results obtained.

CONCLUSIONS: Removal of perchloroethyelene (PCE) is less efficient than that obtained during the electrolysis of synthetic solutions of this chlorinated pollutant and there are two first order kinetic zones, which indicate an important competition for the oxidation of the different organics contained in the soil washing fluid during the 


\section{Keywords}

27 Perchloroethylene; soil washing; electrolysis; diamond anodes

28

Highlights

30

- Combined soil washing and anodic oxidation can treat successfully polluted soils

- Perchloroethylene can be extracted from soils spiked with oils by soil washing with SDS.

- Strong interactions of the SDS with soil and pollutants.

34

- Anodic oxidation with diamond can remove perchloroethylene from soil-washing

35 fluids

36

- Degradation kinetic is slower when treating soil-washing fluid than synthetic solutions of perchloroethylene.

38

39

40

41

42

43

44

45

46 *author to whom all correspondence should be addressed: manuel.rodrigo@uclm.es 


\section{Introduction}

49

50

51

52

53

54

55

In recent years, remediation of soil and groundwater polluted with chlorinated hydrocarbons has gained a lot of interest, as emphasized by EU and national regulations concerning clean-up of pollutants sites. Numerous studies were carried out to face this great challenge evaluating, among other technologies, bioremediation 1, soil-vapor extraction, ozone oxidation ${ }^{2}$, surfactant soil washing ${ }^{3}$, dehalogenation ${ }^{4}$, electrokinetics ${ }^{5-}$ ${ }^{8}$, etc. Unfortunately, each of these processes exhibit different technical or cost limitations and up to now, not a clear solution is found to this important problem.

In this context, promising results are being obtained by combining some of these technologies with Electrochemical Advanced Oxidation Processes (EAOPs) ${ }^{9-12}$. Among them, the combination of anodic oxidation with surfactant-aided soil-washing (SASW) ${ }^{3}$ is particularly interesting, because it helps to obtain good performance in the extraction and destruction of hydrophobic compounds from soil. Soil washing is generally efficient to clean soil. It has been exhaustively studied in our research group in previous works ${ }^{13-}$ 17, attaining good results in the depletion of target compounds both, from the soil matrix and later from soil washing fluid (SWF) using anodic oxidation. Regarding the SASW process, special care should be taken with the selection of optimal washing fluid composition, volume, mixing rate, temperature and contact time ${ }^{3}$. The addition of extracting agents (typically surfactants) and their concentration is key to extract pollutants in efficient conditions. Additionally, the recovery of extracting agents once the treatment is carried out is another goal to develop sustainable and cost-effective processes with high removal efficiency.

Once produced the soil washing waste, among the AOPs which can be applied for its removal, electrolysis with diamond electrodes has reached a special level of interest, because of the outstanding performance ${ }^{18}$. It has been applied successfully to the 
degradation of many types of pollutants, attaining in most cases a very high efficiency ${ }^{19-}$ 22.

Perchloroethylene (PCE) is one of the most known chlorinated organic compounds and is among the most common pollutants at industrial sites, because for decades, it has been extensively applied as solvent in metal processing, chemical production and dry cleaning processes. Due to their volatility, it readily escapes from production plants and it is frequently detected in polluted soil and groundwater ${ }^{23}$, typically associated to accidental spill of wastes. The United States Environment Protection Agency (EPA) has classified this species as a probable human carcinogen and this has motivated that the maximum level of PCE has been set at $5 \mu \mathrm{g} \mathrm{dm}^{-3}$ under Safe Drinking Water Act (U.S. EPA 2009) 24.

The removal of PCE has been faced by lots of authors, using not only biological systems 4, 25-27, but also different AOPs such as Fenton process ${ }^{28}$, oxidation with activated persulfate in a porous media ${ }^{29}$, sodium percarbonate and iron ${ }^{24}$ and, recently, through the non-thermal plasma, promoting the generation of highly reactive oxidants in contact with water and gases ${ }^{30}$. The treatment of this ubiquitous pollutant and possible intermediates can also be obtained by reductive dehalogenation and recent works, in which Zero-valent Iron (ZVI) is used as reductive agent, are of a great interest ${ }^{31-35}$. Regarding the application of electrochemical techniques for their removal, there are various previous studies focused on the selection of anodic and cathodic strategies to remove $\mathrm{PCE}^{36}$ and sonoelectrochemical degradation of PCE in aqueous sodium sulphate

$94 \quad 37$ and in absence of background electrolyte ${ }^{38}$. However, to our best knowledge, studies were not carried out combining this PCE soil-washing with the anodic oxidation of the washing waste obtained. 
Therefore, the development of efficient technologies for the remediation of soils polluted with organochlorinated species is still a very important environmental issue and the goal of this work is to evaluate the removal of PCE from spiked soils polluted also with oils (to simulate a real PCE-industrial polluted soil) by using surfactant soil washing and electrolysis with diamond anodes. This treatment was successfully applied for the remediation of soils polluted with clopyralid and lindane in previous works of our group 16, 39, two species with very different properties of that exhibited by PCE, which is typically associated to the presence of oils. In this case of the complexity is higher due to the presence of not only soluble species but of micelles of SDS with PCE and oils.

Thus, in this work, the complexity of the treatment is greater because of the presence of oils in the soil, which is a typical case in many industrial polluted sites, because PCE has been commonly used for decades as a solvent to degrease pieces in the metal mechanic industry.

\section{Materials and methods}

Chemicals. Tetrachloroethylene $\left(\mathrm{C}_{2} \mathrm{Cl}_{4},>99 \%\right)$, Sodium Dodecyl Sulphate (SDS) (used as solubilizing agent) and Hexane (Sigma Aldrich, Spain) HPLC grade were obtained from Sigma Aldrich and used for GC-ECD. A hydrophobic lubricant oil Serie FORTE was obtained from Josval (Zaragoza, Spain). Methanol was obtained from VWR. Double deionized water (Millipore Milli-Q System, resistivity: $18.2 \mathrm{M} \Omega \mathrm{cm}$ at $25^{\circ} \mathrm{C}$ ) was used to prepare soil-washing fluid.

Analytical techniques. To determine tetrachloroethylene concentration in the liquid phase, an $\mathrm{L}-\mathrm{L}$ extraction process was used before the analytical analysis. This process was carried out in separator flasks of $10 \mathrm{~cm}^{3}$ using hexane as extraction solvent (v/v ratio tetrachloroetylene/solvent 4 ). After that, all samples extracted from electrolyzed solution were filtered with $0.22 \mu \mathrm{m}$ nylon filters before analysis. The removal of 
123 (GC-ECD) (Thermo Fisher Scientific), using a TG-5MS capillary column $(30 \mathrm{~m} \times 0.25$ mm $0.25 \mathrm{~mm}), 63 \mathrm{Ni}$ micro-electron capture detector, a split/splitless injector and was $0.1 \mathrm{mg} \mathrm{dm}^{-3}$. The flow rate of gas He was $1.0 \mathrm{~cm}^{3} \mathrm{~min}^{-1}$. The temperature of the oven was programmed as follows: $65^{\circ} \mathrm{C}$ kept for 1 minute, then increased to $140^{\circ} \mathrm{C}$ at $15^{\circ} \mathrm{C}$ $\min ^{-1}$ followed by another ramp to reach $2900^{\circ} \mathrm{C}$ followed by 2 minutes hold. The temperature of the injector was $260 \stackrel{\circ}{ }{ }^{\circ}$. Particle size was measured using a Mastersizer Hydro 2000SM (Malvern). Measurements of $\mathrm{pH}$ and conductivity were measured using a CRISON pH25+ and CRISON CM35+. Zeta potential was also measured for the clarified liquid and the homogeneous sample using a Zetasizer Nano ZS (Malvern, UK).

A colorimetric method was used to determine the concentration of the SDS surfactant ${ }^{40}$.

The anions present in the target wastewater were characterized using ion chromatography by means of a Shimadzu LC-20A system ${ }^{16}$.

Soil Washing. In this work, samples of $1 \mathrm{Kg}$ of soil were uniformly polluted with batch tank as described elsewhere ${ }^{41}$.

Table 1 . Physico-chemical properties of low permeability soil.

\begin{tabular}{|c|c|c|c|}
\hline \multicolumn{2}{|c|}{ Mineralogy (\%) } & \multicolumn{2}{c|}{ Particle size distribution (\%) } \\
\hline Kaolinite & 26 & Gravel & 0 \\
\hline Feldspars & 15 & Sand & 4 \\
\hline TiO $_{2}$ & 0.27 & Silt & 18 \\
\hline Calcite & 4 & Clay & 78 \\
\hline $\mathbf{K}_{\mathbf{2}} \mathbf{O}$ & 0.75 & Specific gravity & 2.6 \\
\hline $\mathbf{S i O}_{\mathbf{2}}$ & 7 & Hydraulic conductivity $(\mathrm{cm} / \mathrm{s})$ & $1 \times 10^{-8}$ \\
\hline $\mathbf{A I}_{\mathbf{2}} \mathbf{O}_{\mathbf{3}}$ & 34.50 & Organic content $(\%)$ & 0 \\
\hline
\end{tabular}




\begin{tabular}{|c|c|c|c|}
\hline Others & 12.48 & $\mathrm{pH}$ & 4.9 \\
\hline
\end{tabular}

145 Soil (amount ranging from 100 to $500 \mathrm{~g}$ ) polluted with $200 \mathrm{mg}$ tetrachloroethylene $\mathrm{kg}^{-1}$ 146 and $1.0 \mathrm{dm}^{3}$ of SWF (concentration of SDS ranging from 100 to $20,000 \mathrm{mg} \mathrm{dm}^{-3}$ ) were 147 mixed using paddle stirrers $\left(\mathrm{G} \approx 4500 \mathrm{~s}^{-1}\right)$ for 24 hours in order to reach stationary 148 conditions in the reactor. Then, the same tank acted as a settler (for $48 \mathrm{~h}$ ) to split up the 149 soil from the washing effluent. The soil washing wastes obtained consisted of complex 150 aqueous-oil mixtures of tetrachloroethylene, surfactant and soil, with emulsified micro 151 drops and soluble species.

Electrolysis. The SASW effluents were treated by electrolysis with diamond anodes using a bench-scale electrochemical setup described elsewhere ${ }^{16}$. Boron doped diamond (BDD) (Adamant Technologies, Switzerland) and stainless-steel electrodes with a geometric area of $78 \mathrm{~cm}^{2}$ were used as anode and cathode, respectively. The characteristics of the BDD used were: $\mathrm{sp}^{3} / \mathrm{sp}^{2}$ ratio: 225 ; boron content: $500 \mathrm{ppm} ; 2-3 \mu \mathrm{m}$ of BDD coating thickness. The cells cover were made of quartz. The inter-electrode gap between both electrodes was approximately $1.6 \mathrm{~mm}$. The SASW effluent obtained after settling was stored in a thermo-regulated glass tank $\left(600 \mathrm{~cm}^{3}\right)$ and circulated through the cell using a peristaltic pump at flow rate of $60 \mathrm{dm}^{3} \mathrm{~h}^{-1}$. This flow through the cell helps to obtain good mixing (by pumping) and a proper regulation of temperature (very important due to the ohmic loses of electrochemical processes). The electric current was applied using a Delta Electronika ES030-10 power supply (0-30V, 0-10 A). The electrolysis was carried out galvanostatically at $50 \mathrm{~mA} \mathrm{~cm}^{-2}$ (which is within the typical range used in literature ${ }^{13-17}$ ). Prior to use in galvanostatic electrolysis assays, the electrode was polarized for $10 \mathrm{~min}$ in a $0.035 \mathrm{M} \mathrm{Na}_{2} \mathrm{SO}_{4}$ solution at $15 \mathrm{~mA} \mathrm{~cm}^{-2}$ to remove any 
167 impurities from its surface. Samples $\left(0.02 \mathrm{dm}^{3}\right)$ were collected in the glass tank and

168 temperature was kept constant by means of a thermo-regulated water bath.

\section{Results and discussion}

171 Soil washing. The first stage in the remediation of soil polluted with perchloroethylene

172 is the extraction of the pollutant from the soil, in order to transfer it into a liquid that can

173 be further processed by oxidation. To do this, it was evaluated a soil washing process

174 using surfactant solutions as soil washing fluids (SWF). As it is known, solubility of 175 perchloroethylene in water is not very high $\left(150 \mathrm{mg} \mathrm{dm}^{-3}\right.$ at $\left.25{ }^{\circ} \mathrm{C}\right)$ and because of that, it is necessary to add a surfactant that helps to produce micelles not only from the perchloroethylene but also from the oil contained in the soil, improving the efficiency of the pollutant extraction. So that, a surfactant was chosen taking into account the impact on the soil and previous results of our group in others SW process with also non polar compounds ${ }^{12}$, and the behavior and extraction efficiency of different kind of surfactant (anionic, cationic and non ionic) ${ }^{11}$. It was chosen an anionic surfactant, sodium dodecyl sulfate (SDS) and it was used in the range 5-20 $\mathrm{g} \mathrm{dm}^{-3}$ evaluating the efficiency of the washing process at different soil /SWF ratios. Thus, the SWFs used in this work consists of different concentrations of SDS in water in order to determine the best ratio between surfactant and pollutant, capable to extract the chlorinated hydrocarbon efficiently from the soil.

Figure 1 shows the distribution of the organochlorinated pollutant perchloroethylene and the surfactant sodium dodecyl sulfate (SDS) after washing different amounts of a spiked soil (ranging from 100 to $500 \mathrm{~g}$ ) with $1.0 \mathrm{dm}^{3}$ of soil washing fluid (SWF), which contained three different concentrations of SDS (ranging from 5 to $20 \mathrm{~g} \mathrm{dm}^{-3}$ ). 
In every case, after mixing vigorously the soil with the SWF and letting the system to settle, not two (as expected) but three phases were observed: 1) a volume of clarified liquid at the top of the tank, 2) a dense sludge with most of the treated soil at the bottom and 3) an interphase between both phases in which a significant amount of soil is contained and which can be explained in terms of the strong interactions of the soil particles and the surfactant. As seen in the Part a, concentration of perchloroethylene in the liquid phase is almost negligible and to extract successfully this pollutant it is required to use highly concentrated SDS as SWF, because otherwise the concentrations remaining in the soil after the soil washing procedure are very large. Even with these high concentrations, most of the perchloroethylene is contained in the interphase. In comparing these results with those obtained in the treatment of clopyralid ${ }^{39}$ or, more recently, with lindane ${ }^{16}$ using the same technology, it should be remarked that in this case the process is clearly more complicated. Thus, in the first case, the pollutant was released completely to the SWF (without needing a surfactant to improve the efficiency) and in the second case (in which the same surfactant was used), almost no interphase was detected so the clarified liquid contained most of the pollutant after the treatment. As it will be seen later on, the large values of the z-potential will help to explain this observation. For this reason, in this case it was needed to separate the clarified liquid and the interphase all together in order to undergo electrolysis and remove the pollutant.

210 Regarding the surfactant, the strong interactions of SDS with soil can also be seen in Part $211 \mathrm{~b}$ of the Figure, where it can be observed that most of the SDS added is retained the soil 212 (even in the bottom or in the interphase) and there is only free SDS in the clarified liquid at low ratios soil /SWF. This result confirms a strong interaction between the SDS and the soil particles. 


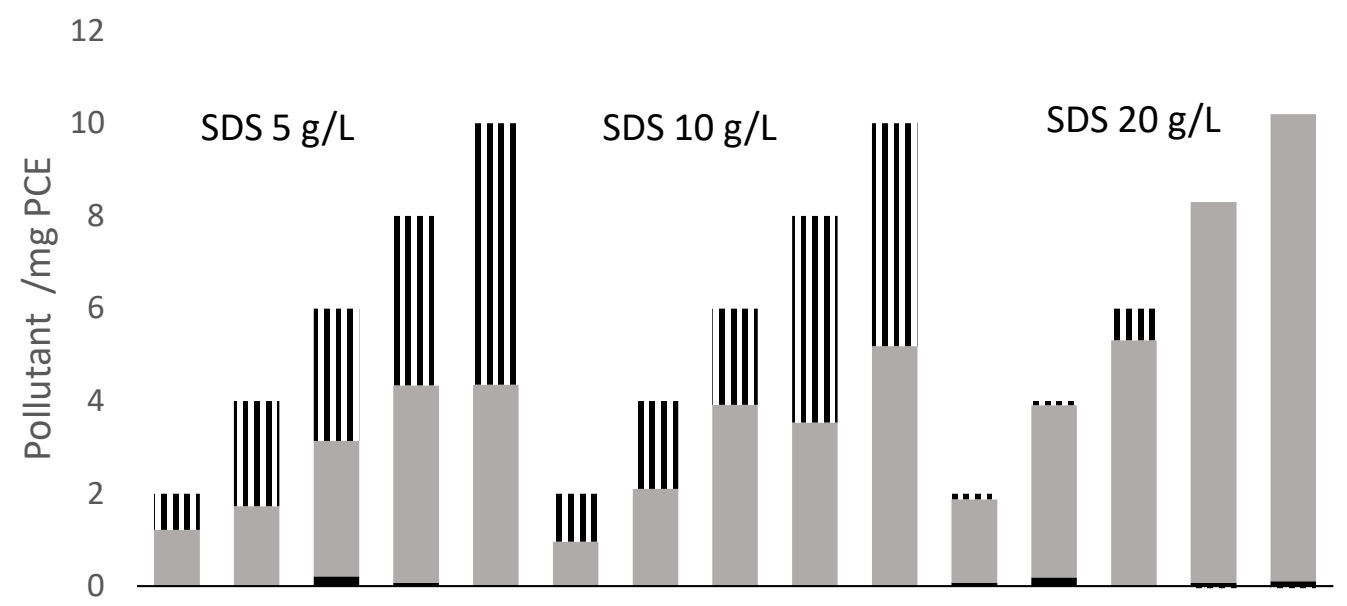

$$
2500
$$

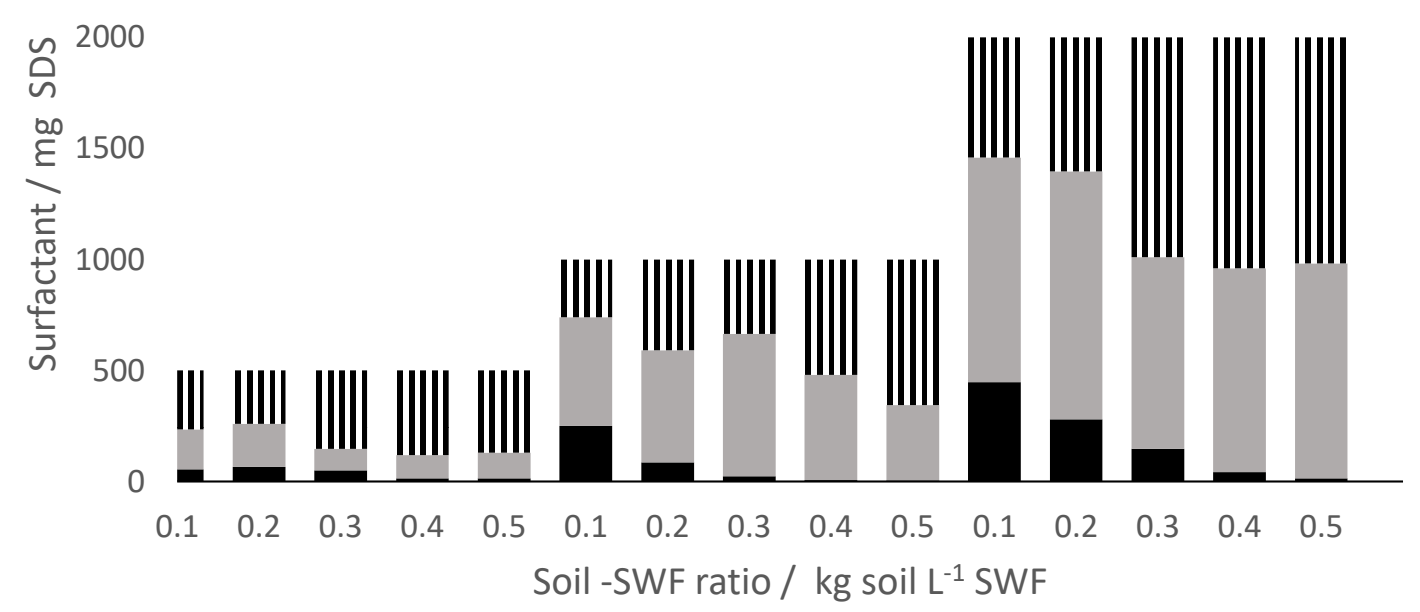

217 Figure 1. Pollutant and surfactant distribution after the application of the SASW process among the soil $(\|\| \|)$, turbid interphase $(\square)$ and clarified liquid $(\boldsymbol{\square})$ during the treatment of soil polluted with $200 \mathrm{mg} \mathrm{dm}^{-3}$ of PCE at different SDS/soil ratios. Concentration of SDS used in the raw soil washing fluid: $5.0 \mathrm{~g} \mathrm{dm}^{-3} ; 10 \mathrm{~g} \mathrm{dm}^{-3} ; 20 \mathrm{~g} \mathrm{dm}^{-3}$.

222 Electrolysis of SWFs. Figure 2 presents the removal of perchloroethylene, oils and SDS

223 from the mixture clarified liquid - soil washing fluid obtained after mixing $200 \mathrm{~g}$ of soil

224 with $1 \mathrm{dm}^{-3}$ of SWF during the electrolysis with diamond anodes. As expected, both the

225 perchloroethylene and the oils are completely removed during the electrolysis, being the removal of the perchloroethylene 4-times faster than that of the oils. In addition, the first 
227 decay (organochlorinated pollutant) is exponential while the second (oil pollutant) clearly

228 fits a linear trend. Hence, combination of surfactant soil washing, and electrolysis seems

229 to be a suitable treatment for the removal of these pollutants from SWF.

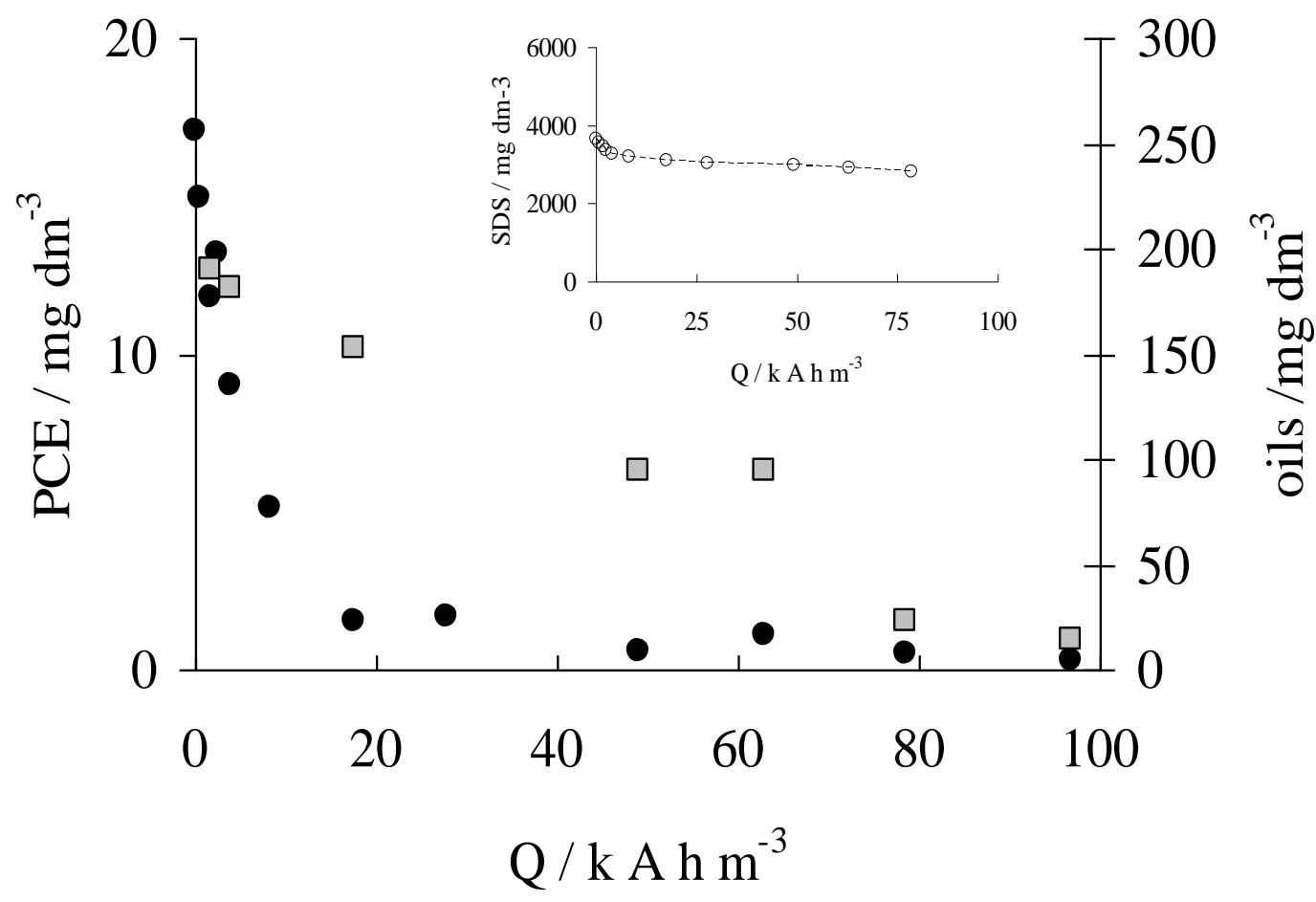

Figure 2. Electrolysis of soil washing effluent obtained after mixing $200 \mathrm{~g}$ of polluted soil

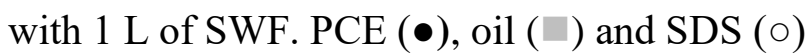

Regarding SDS, its removal is less favoured and, although this molecule undergoes oxidation and the concentration decreases by more than $800 \mathrm{mg} \mathrm{dm}^{-3}$ during the test, the removal is only marginal as compared to that of PCE and oils, which are almost completely depleted during the treatment. It is important to point out that the removal of SDS is faster just during the period in which PCE is present in the system, in which more than $500 \mathrm{mg} \mathrm{dm}^{-3}$ are removed for charges under $20 \mathrm{k} \mathrm{h} \mathrm{m}^{-3}$ and then, the rate becomes much slower. This might suggest the more effective oxidation of the micelles with PCE 
at the initial moments and that after the removal of these micelles, the removal of SDS that it is interacting with soil should become slower because of some sort of protective role for the soil particles, as it will be pointed out later on.

245 Focusing on the low removal of SDS, Part a of Figure 3 shows the changes in the distribution of SDS between the clarified liquid (obtained after sedimentation) and the interphase (with most of the soil particles). Additionally, Part b of this Figure indicates the values of the $\mathrm{z}$ potential of the total treated liquid and of the clarified phase. In addition, it also gives other relevant information about soils behavior during the electrolysis including the ratio between the clarified and the decanted phases and the total suspended solid concentrations. Both panels of this figure have been coloured with the purpose of marking the complex the periods in which the most important changes ocurr in the system.

As observed, there are strange changes in the distribution of this surfactant (which it is important to remind that it is not a real pollutant, but it was added to extract the pollutants between the clarified and the interphase), with a sudden and fast transfer of the SDS from the clarified to the interphase, which is later reverted and, then, it continues over the complete electrolysis. They indicate a similar predisposition of SDS to form micelles or to interact with soils. These changes seem to have a protective role on the oxidation of SDS (in particular the interaction with soil particles) which seems to be disfavored in comparison with that of the other organics contained. As seem, the two other parameters shown in the Part $b$ seem to change during this first stage in the same fashion. $Z$ potentials are negative at the beginning of the electrolysis but they become even more negative during this first stage (in particular in the soil) and then, they started to increase recovering at the end of the test the initial value. When the system reached the lowest $\mathrm{z}$ potential, the separation of the clarified liquid was less efficient and the concentration of total suspended solid (that initially was not expected to change) exhibits also a lower value, 
269 particles.

270

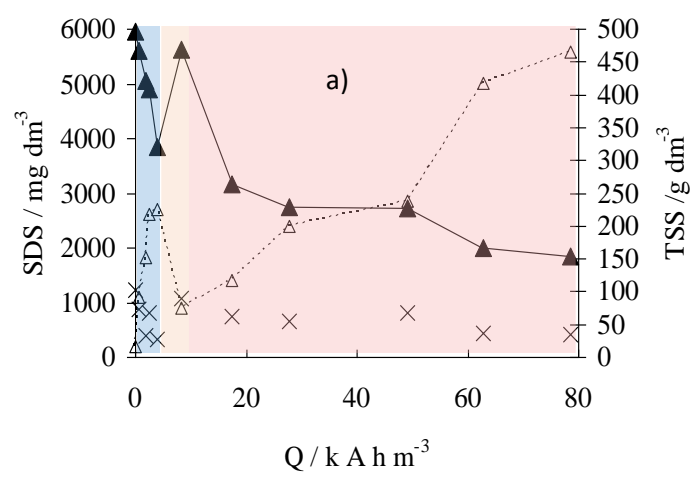

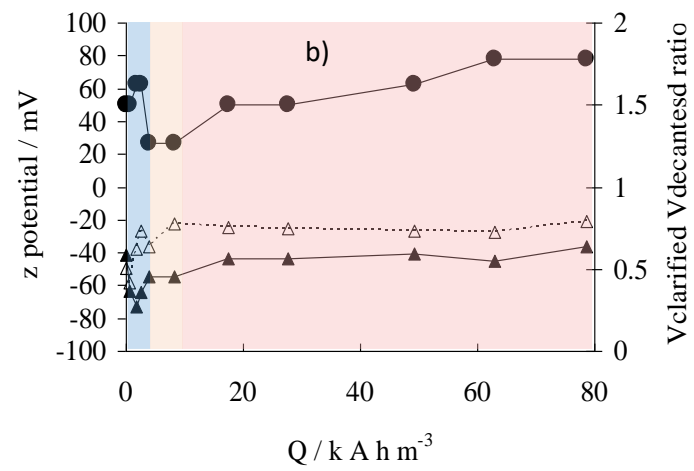

271

272

273

274

Figure 3. Part a) Distribution of SDS in the clarified liquid $(\Delta)$ and in the intherphase $(\boldsymbol{\Delta})$ and the evolution of total suspended solids (TSS)( $\mathbf{m})$ with the applied electric charge. Part b) Evolution of zeta potential of the clarified liquid $(\Delta)$ and of the interphase $(\boldsymbol{\Delta})$ and the ratio of volume clarified and decanted $(\bullet)$ with the applied electric charge.

This behavior was reproducible and it was also obtained in the treatment of other SWFs obtained in this work. Thus, Figure 4 indicates changes in the $\mathrm{pH}$, conductivity, particle size $\left(\mathrm{d}_{50}\right.$ an $\left.\mathrm{d}_{90}\right)$ and SDS measured in the clarified phase during the electrolysis carried out to SWF obtained after treating 200 and $300 \mathrm{~g}$ of soil with $1 \mathrm{dm}^{-3}$ of SWF. This latter three parameters are only shown for the first $40 \mathrm{kAh} \mathrm{m}^{-3}$, in order to allow the evaluation of the two first zones, in which most of the relevant changes happens (otherwise data are shown as overlapped). The $\mathrm{pH}$ decreases very rapidly in both cases and this change seems to be the driving force for the changes in the SDS concentrations, sedimentability and in the particle size, which follow the same pattern: decreases very rapidly and them increases up to a maximum, from which it finally decreases again down to the average value of the soil particle size. This change indicates a huge change during the electrolysis in the micelles composition obtained after the soil washing. The change can start with the decrease in the $\mathrm{pH}$, which favors the transfer of the surfactant to the soil and allows the 


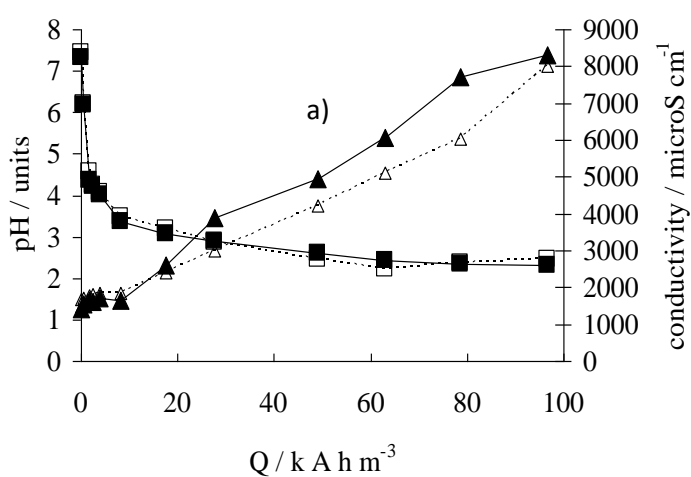
prevents its oxidation. rapid adsorption of anions in order to compensate charges (as will seen with sulfate concentration in the next Figure). Then, the micelles are oxidized and recombined to form again larger micelles, which are oxidized completely at the same time that the perchloroethylene and oils contained in them. SDS released from the attack to micelles is not in the clarified liquid but it strongly interacts with the soil particles and this interaction

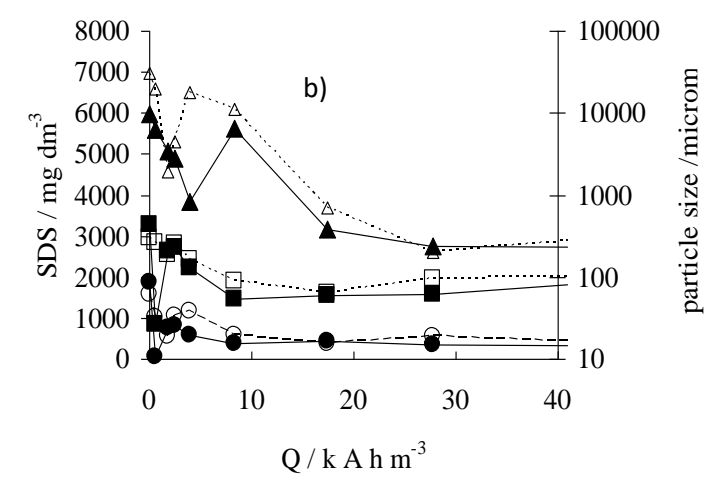

Figure 4. Electrolysis of soil washing effluents obtained at ratios soil-surfactant solutions of 200 (full points) and $300 \mathrm{~g}$ soil $\mathrm{L}^{-1}$ SWF (empty points). a). Changes in $\mathrm{pH}(\square$ ) and conductivity $(\Delta \boldsymbol{\Delta})$; b) Changes in the particle size $\left(\mathrm{d}_{50} \bullet\right.$ and $\left.\mathrm{d}_{90} \boldsymbol{\square}\right)$ and SDS concentration In order to fully understand the process, the interpretation in the changes in the concentration of other species is important. Figure 5 shows changes in the ion concentrations during the electrolysis. As seen, sulfate undergoes a rapid decrease in its concentration which matches with the decrease in the Z-potential and supports the previous explanation about the redistribution of micelles during the very beginning of the electrolysis. Then, it is observed an increase, which is consistent with the removal of SDS. Chloride increases its concentration in the first stage as a consequence of the degradation 
sequentially oxidized to hypochlorite, chlorate and perchlorate. However the

309 concentrations of hypochlorite are much lower than that of oxidants produced. This

310 indicates that in addition to this oxochlorinated anion, other oxidants are being formed in

311 the reaction media, being persulfate the most plausible species as it was also pointed out

312 in the literature $\left({ }^{16}\right)$.
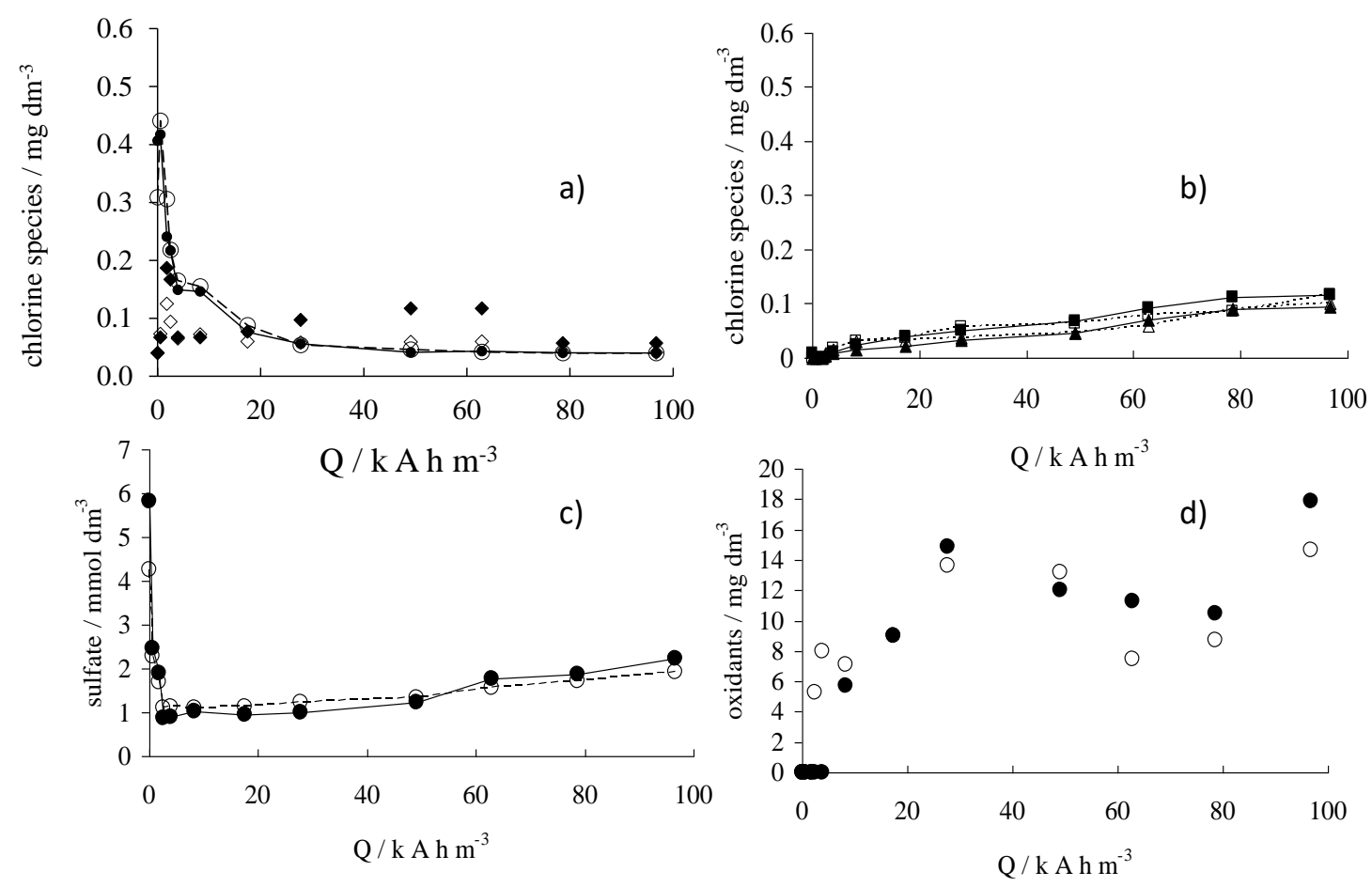

313

314 Figure 5. Evolution of ionic species during the electrolysis of soil washing effluents carried out at soil-surfactant solutions of 200 (full points) and $300 \mathrm{~g}$ soil L ${ }^{-1}$ SWF (empty points). a) $\bigcirc, \bullet$ Chloride; $\diamond, \diamond$ hypochlorite; b) $\boldsymbol{\square}, \square$ chlorate; $\triangle, \boldsymbol{\Delta}$ perchlorate; c) $\bigcirc$, $\bullet$ sulfate; d) $\bigcirc, \bullet$ oxidants.

319 Figure 6 compares the removal of PCE during the oxidation of the soil washing fluids 320 obtained with ratios soil /SWF $0.3 \mathrm{~kg} \mathrm{~L}^{-1}$ and $0.2 \mathrm{~kg} \mathrm{~L}^{-1}$. Except for the higher concentrations drawn in the case of the higher ratio, no differences are observed in the 


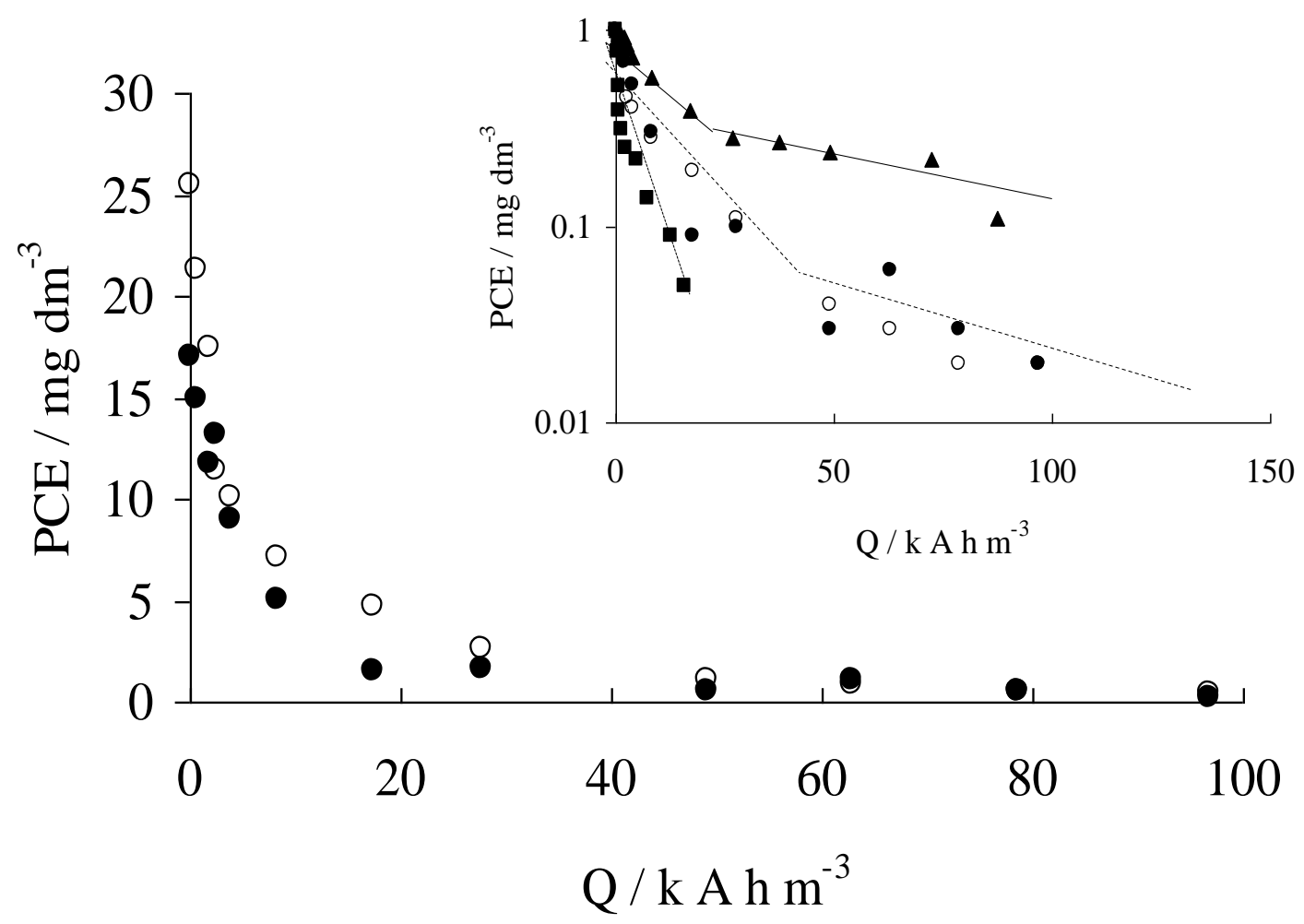

Figure 6. Removal of PCE during the oxidation of soil washing fluid obtained with ratios $300 \mathrm{~g}$ soil L-1 SWF $200 \mathrm{~g}$ soil L-1 SWF. Comparison between the oxidation of these solutions with those of synthetic solution of PCE with $3000 \mathrm{mg} \mathrm{dm}^{-3} \mathrm{of} \mathrm{NaCl}(\mathbf{\square})$ and lindane soil washing solution obtained by using $200 \mathrm{~g}$ soil $\mathrm{L}^{-1} \mathrm{SWF}(\boldsymbol{\Delta})$.

Regarding kinetics, the results does not fit the expected first order kinetic. Thus, as a consequence of the competition between the removal of perchloroethylene, oils and SDS, the removal rate of perchloroethylene does not perfectly fits a first order kinetic but instead of these two regions are found. This rate is much lower than that obtain during the electrolysis of a synthetic solution containing perchloroethylene in the absence of SDS 
to be more efficient than the removal of lindane obtained by soil washing with the same ratio SDS/pollutant pointing out the good performance of the electrolysis for the treatment of this pollutant ${ }^{16}$. In addition, during that electrolysis of lindane, the same two zones were observed pointing out the similarities between performance of the technology with two very different pollutants.

\section{Conclusions}

From this work the following conclusions can be drawn:

- Combined soil washing and electrolysis with diamond anodes can be used to remove PCE and oils from soils. High concentrations of SDS are required in the soil washing fluid for an efficient extraction of the chlorinated hydrocarbon and this forces to apply electrolysis not only to the clarified liquid but to also to the interphase, where most of the pollutant is concentrated

- SDS interacts strongly with soil not only during the washing step but also during the electrolysis. This interaction seems to play a protective role against the oxidation of SDS. First moments of the electrolysis are rather complex and there are several processes which modifies importantly the results.

- Removal of PCE is less efficient than that obtained during the electrolysis of synthetic solutions of this chlorinated pollutant. There are two first order kinetic zones, which indicate competition in the electrolysis.

\section{Acknowledgments}


Financial support from the Spanish Ministry of Economy, Industry and Competitiveness,

European Union through project CTM2016-76197-R (AEI/FEDER, UE) and the Spanish

360 Government (Grant № FPU16/00067) are gratefully acknowledged.

361

\section{References}

1. Volpe A, Del Moro G, Rossetti S, Tandoi V and Lopez A, Remediation of PCEcontaminated groundwater from an industrial site in southern Italy: A laboratory-scale study. Process Biochemistry 42: 1498-1505 (2007).

2. Sunder $M$ and Hempel D-C, Oxidation of tri- and perchloroethene in aqueous solution with ozone and hydrogen peroxide in a tube reactor. Water Research 31: 33-40 (1997).

3. Trellu C, Mousset E, Pechaud Y, Huguenot D, van Hullebusch ED, Esposito G and Oturan MA, Removal of hydrophobic organic pollutants from soil washing/flushing solutions: A critical review. Journal of Hazardous Materials 306: 149-174 (2016).

4. Hirl PJ and Irvine RL, Reductive dechlorination of perchloroethylene using anaerobic sequencing batch biofilm reactors (AnSBBR). Water Science and Technology 35: 49-56 (1997).

5. Cameselle $\mathrm{C}$ and Reddy KR, Effects of Periodic Electric Potential and Electrolyte Recirculation on Electrochemical Remediation of Contaminant Mixtures in Clayey Soils. Water Air and Soil Pollution 224 (2013).

6. Li D, Sun D, Hu S, Hu J and Yuan X, Conceptual design and experiments of electrochemistry-flushing technology for the remediation of historically $\mathrm{Cr}(\mathrm{VI})$ contaminated soil. Chemosphere 144: 1823-1830 (2016).

7. Hahladakis JN, Calmano W and Gidarakos E, Use and comparison of the non-ionic surfactants Poloxamer 407 and Nonidet P40 with HP-beta-CD cyclodextrin, for the enhanced electroremediation of real contaminated sediments from PAHs. Separation and Purification Technology 113: 104-113 (2013).

8. Hahladakis JN, Lekkas N, Smponias A and Gidarakos E, Sequential application of chelating agents and innovative surfactants for the enhanced electroremediation of real sediments from toxic metals and PAHs. Chemosphere 105: 44-52 (2014).

9. Huguenot D, Mousset E, van Hullebusch ED and Oturan MA, Combination of surfactant enhanced soil washing and electro-Fenton process for the treatment of soils contaminated by petroleum hydrocarbons. Journal of Environmental Management 153: 40-47 (2015).

10. dos Santos EV, Sáez C, Cañizares P, Martínez-Huitle CA and Rodrigo MA, UV assisted electrochemical technologies for the removal of oxyfluorfen from soil washing wastes. Chemical Engineering Journal 318: 2-9 (2017).

11. López-Vizcaíno R, Sáez C, Cañizares $P$ and Rodrigo MA, The use of a combined process of surfactant-aided soil washing and coagulation for PAH-contaminated soils treatment. Separation and Purification Technology 88: 46-51 (2012).

12. Gu X, Lu S, Qiu Z, Sui Q, Banks CJ, Imai T, Lin K and Luo Q, Photodegradation performance of 1,1,1-trichloroethane in aqueous solution: In the presence and absence of persulfate. Chemical Engineering Journal 215-216: 29-35 (2013).

13. Almazán-Sánchez PT, Cotillas S, Sáez C, Solache-Ríos MJ, Martínez-Miranda V, Cañizares $P$, Linares-Hernández I and Rodrigo MA, Removal of pendimethalin from soil washing effluents using electrolytic and electro-irradiated technologies based on diamond anodes. Applied Catalysis B: Environmental 213: 190-197 (2017). 
14. dos Santos EV, Sáez C, Cañizares P, da Silva DR, Martínez-Huitle CA and Rodrigo MA, Treatment of ex-situ soil-washing fluids polluted with petroleum by anodic oxidation, photolysis, sonolysis and combined approaches. Chemical Engineering Journal 310, Part 2: 581-588 (2017).

15. dos Santos EV, Saez C, Martinez-Huitle CA, Canizares P and Rodrigo MA, Removal of oxyfluorfen from ex-situ soil washing fluids using electrolysis with diamond anodes. $J$ Environ Manage 171: 260-266 (2016).

16. Muñoz-Morales M, Braojos M, Sáez C, Cañizares P and Rodrigo MA, Remediation of soils polluted with lindane using surfactant-aided soil washing and electrochemical oxidation. Journal of Hazardous Materials 339: 232-238 (2017).

17. Chair K, Bedoui A, Bensalah N, Fernandez-Morales FJ, Saez C, Canizares P and Rodrigo $M A$, Combining bioadsorption and photoelectrochemical oxidation for the treatment of soil-washing effluents polluted with herbicide 2,4-D. Journal of Chemical Technology and Biotechnology 92: 83-89 (2017).

18. Panizza M, Cerisola $\mathrm{G}$, Direct and mediated anodic oxidation of organic pollutants. Chemical Reviews 109: 6541-6569 (2009).

19. Sirés I, Brillas E, Oturan MA, Rodrigo MA and Panizza M, Electrochemical advanced oxidation processes: today and tomorrow. A review. Environmental Science and Pollution Research 21: 8336-8367 (2014).

20. Martínez-Huitle CA, Rodrigo MA, Sirés I and Scialdone O, Single and Coupled Electrochemical Processes and Reactors for the Abatement of Organic Water Pollutants: A Critical Review. Chemical Reviews 115: 13362-13407 (2015).

21. Martinez-Huitle CA and Brillas E, Decontamination of wastewaters containing synthetic organic dyes by electrochemical methods: A general review. Applied Catalysis BEnvironmental 87: 105-145 (2009).

22. Brillas E and Martínez-Huitle CA, Decontamination of wastewaters containing synthetic organic dyes by electrochemical methods. An updated review. Applied Catalysis B: Environmental 166-167: 603-643 (2015).

23. Hofstee C, Oostrom M, Dane JH and Walker RC, Infiltration and redistribution of perchloroethylene in partially saturated, stratified porous media1Contribution from the Alabama Agric. Exp. Stn., Auburn University, AL, USA.1. Journal of Contaminant Hydrology 34: 293-313 (1998).

24. Miao Z, Gu X, Lu S, Zang X, Wu X, Xu M, Ndong LBB, Qiu Z, Sui Q and Fu GY, Perchloroethylene (PCE) oxidation by percarbonate in Fe2+-catalyzed aqueous solution: PCE performance and its removal mechanism. Chemosphere 119: 1120-1125 (2015).

25. Tabernacka A and Zborowska E, Trichloroethylene and tetrachloroethylene elimination from the air by means of a hybrid bioreactor with immobilized biomass. Journal of Bioscience and Bioengineering 114: 318-324 (2012).

26. Yoshida N, Asahi K, Sakakibara Y, Miyake K and Katayama A, Isolation and quantitative detection of tetrachloroethene (PCE)-dechlorinating bacteria in unsaturated subsurface soils contaminated with chloroethenes. Journal of Bioscience and Bioengineering 104: 91-97 (2007).

27. Andrew James C, Xin G, Doty SL, Muiznieks I, Newman L and Strand SE, A mass balance study of the phytoremediation of perchloroethylene-contaminated groundwater. Environmental Pollution 157: 2564-2569 (2009).

28. Jho $\mathrm{EH}$, Singhal $\mathrm{N}$ and Turner $\mathrm{S}$, Fenton degradation of tetrachloroethene and hexachloroethane in Fe(II) catalyzed systems. Journal of Hazardous Materials 184: 234240 (2010).

29. Zheng F, Gao B, Sun Y, Shi X, Xu H, Wu J and Gao Y, Removal of tetrachloroethylene from homogeneous and heterogeneous porous media: Combined effects of surfactant 
solubilization and oxidant degradation. Chemical Engineering Journal 283: 595-603 (2016).

30. Karimaei M, Nabizadeh R, Shokri B, Khani MR, Yaghmaeian K, Mesdaghinia A, Mahvi A and Nazmara S, Dielectric barrier discharge plasma as excellent method for Perchloroethylene removal from aqueous environments: Degradation kinetic and parameters modeling. Journal of Molecular Liquids 248: 177-183 (2017).

31. Tosco T, Petrangeli Papini M, Cruz Viggi C and Sethi R, Nanoscale zerovalent iron particles for groundwater remediation: a review. Journal of Cleaner Production 77: 1021 (2014).

32. Fagerlund F, Illangasekare TH, Phenrat T, Kim HJ and Lowry GV, PCE dissolution and simultaneous dechlorination by nanoscale zero-valent iron particles in a DNAPL source zone. Journal of Contaminant Hydrology 131: 9-28 (2012).

33. Kim H, Hong H-J, Jung J, Kim S-H and Yang J-W, Degradation of trichloroethylene (TCE) by nanoscale zero-valent iron ( $\mathrm{nZVI}$ ) immobilized in alginate bead. Journal of Hazardous Materials 176: 1038-1043 (2010).

34. Kim H, Hong H-J, Lee Y-J, Shin H-J and Yang J-W, Degradation of trichloroethylene by zero-valent iron immobilized in cationic exchange membrane. Desalination 223: 212220 (2008).

35. Amir A and Lee W, Enhanced reductive dechlorination of tetrachloroethene by nanosized zero valent iron with vitamin B12. Chemical Engineering Journal 170: 492-497 (2011).

36. Sáez V, Esclapez Vicente MD, Frías-Ferrer ÁJ, Bonete P and González-García J, Electrochemical degradation of perchloroethylene in aqueous media: An approach to different strategies. Water Research 43: 2169-2178 (2009).

37. Sáez V, Esclapez MD, Tudela I, Bonete P, Louisnard O and González-García J, 20kHz sonoelectrochemical degradation of perchloroethylene in sodium sulfate aqueous media: Influence of the operational variables in batch mode. Journal of Hazardous Materials 183: 648-654 (2010).

38. Sáez V, Tudela I, Esclapez MD, Bonete P, Louisnard O and González-García J, Sonoelectrochemical degradation of perchloroethylene in water: Enhancement of the process by the absence of background electrolyte. Chemical Engineering Journal 168: 649-655 (2011).

39. Cotillas S, Cañizares L, Muñoz M, Sáez C, Cañizares P and Rodrigo MA, Is it really important the addition of salts for the electrolysis of soil washing effluents? Electrochimica Acta 246: 372-379 (2017).

40. Jurado E, Fernández-Serrano M, Núñez-Olea J, Luzón $G$ and Lechuga $M$, Simplified spectrophotometric method using methylene blue for determining anionic surfactants: Applications to the study of primary biodegradation in aerobic screening tests. Chemosphere 65: 278-285 (2006).

41. dos Santos EV, Saez C, Martinez-Huitle CA, Canizares P and Rodrigo MA, The role of particle size on the conductive diamond electrochemical oxidation of soil-washing effluent polluted with atrazine. Electrochemistry Communications 55: 26-29 (2015). 